\title{
Endoscopic Endonasal Approach for Craniopharyngiomas
}

\author{
Hamdy M. Behairy ${ }^{\mathrm{a}}$, Adel R. Almelesy ${ }^{\mathrm{b}}$ and Mohamed M. Daoush ${ }^{\mathrm{c}}$ \\ ${ }^{a}$ Neurosurgery Department, Faculty of Medicine, Al-Azhar University, Cairo, ${ }^{b}$ Neurosurgery Department, \\ Faculty of Medicine, Al-Azhar University, Cairo, ${ }^{c}$ Neurosurgery Department, Shebin El Kom Teaching \\ Hospital, Egypt \\ *Corresponding author: Mohamed M. Daoush, E-mail: address: drdaoush2015@gmail.com, Mobile: (+20)01154430504
}

\begin{abstract}
Background: Craniopharyngiomas are challenging tumors that most frequently occur in the sellar or suprasellar regions. The endoscopic endonasal transsphenoidal approach is a minimal-invasive technique for managing craniopharyngiomas.

Objective: The aim of this study was to evaluate endoscopic endonasal trans-sphenoidal approach in management of craniopharyngioma as regard the indications, operative difficulties, post-operative complications and outcomes. Patients and methods: An analytical prospective study conducted on 10 Craniopharyngioma patients treated via endoscopic endonasal, trans-sphenoid approach in Al-Azhar University Hospitals. Follow up of patients done clinically and radiologically over 6 months.

Results: The study included 10 patients, 2 (20\%) males and 8 (80\%) females. Ages ranged from 19 to 60 years (mean age 39.5 years). Gross total resection was achieved in 7 patients (70\%). The most common surgical complications in our series were diabetes insipidus (DI) and cerebrospinal fluid (CSF) leakage in 5 patients (50\%) and 3 patients (30\%) respectively. None of our patients suffered from worsening of endocrinological or visual outcome postoperatively.

Conclusion: To conclude that endoscopic endonasal approach (EEA) is an effective surgical treatment for removal of craniopharyngiomas in terms of surgical outcome and tumor control.

Keywords: Craniopharyngioma, Endoscopy, Skull base surgery, Endoscopic Endonasal Approach, Transsphenoidal surgery.
\end{abstract}

\section{INTRODUCTION}

Craniopharyngiomas are benign tumors that arise from squamous epithelial remnants of Rathke's pouch. These account for approximately $2-5 \%$ of all intracranial tumors and approximately $5.6-13 \%$ in children. The overall incidence of craniopharyngiomas 1.3 per million person/year. A bimodal age distribution has been noted with peak incidence rates in childhood at 5-14 years and in adulthood at 50-74 years. Craniopharyngiomas are rare in newborns and infants with only $5 \%$ arising in patients between birth and 5 years old ${ }^{(\mathbf{1})}$.

According to a histologic finding, adamantinomatous and papillary subtypes have been defined. From a histopathological perspective, craniopharyngiomas are considered to have benign pathologies. Local adhesiveness, tendency to create a mass effect, high surgical failure rates, and increased mortality/morbidity risks of repetitive surgeries may lead these potentially aggressive tumors to be considered "malignant" from surgical and clinical points of view ${ }^{(2)}$.

Intrasellar and infra-diaphragmatic lesions could be resected through an endonasal approach. With the advent of endoscopic endonasal surgery (EES), suprasellar and select intraventricular tumors, which were accessible only using craniotomy, can now be resected using endoscopic endonasal surgery often with improved clinical outcomes compared to transcranial resection ${ }^{(3)}$. CSF leak remains the most pronounced disadvantage of endoscopic endonasal surgery when compared to transcranial approaches, which managed by nasoseptal flaps and multilayer repairs ${ }^{(4)}$.

Radiation therapy is often advocated for residual or recurrent craniopharyngioma following surgical resection to prevent local recurrence. However, radiation therapy is not always effective and may render tumors more difficult to remove ${ }^{(5)}$.

\section{AIM OF THE STUDY}

Evaluation of endoscopic endonasal trans-sphenoidal approach in management of craniopharyngioma as regard the indications, operative difficulties, postoperative complications and outcomes.

\section{PATIENTS AND METHODS}

Patents:

An analytical prospective study conducted on 10 Craniopharyngioma patients that were treated via endoscopic endonasal, trans-sphenoidal approach in Al-Azhar University Hospitals. Follow up of patients done clinically and radiologically over 6 months.

Inclusion criteria: Sellar, Suprasellar, Infradiaphragmatic and sub-chiasmatic Craniopharyngioma in adult patients and de novo cases (not operated before).

Exclusion criteria: Pediatric patients below 18 years, recurrent cases, other sites of craniopharyngioma as intraventricular, sub-frontal, posterior fossa etc... Contraindications of endoscopic endonasal approach as 
nasal deformities, fractures and nasal infections. General contraindications of surgery as coagulation problems and associated intracranial lesions.

\section{Methods:}

\section{A) Pre-operative evaluation:}

- Clinical assessment of Neurological symptoms including visual affection (diminution of vision, visual field changes, blurring of vision, diplopia), symptoms of increased intracranial tension information communication technology (ICT) (Headache, diminution of vision, vomiting, fits), symptoms of motor or sensory affection, autonomic dysfunction, cranial nerves affection, cognitive function defects and disturbed conscious level (DCL). Also, symptoms of hypothalamic-pituitary affection including: obesity, fatigability, amenorrhea, disturbance of sleep and polyuria \& polydipsia.

- Laboratory investigations including: complete blood count (CBC), liver functions, kidney functions, fasting and postprandial blood sugar, serum electrolytes. In addition, hormonal assays (preoperative and postoperative) including: basal serum level of growth hormone $(\mathrm{GH})$, prolactin $(\mathrm{Prl}), \mathrm{T} 3, \mathrm{~T} 4, \mathrm{TSH}, \mathrm{FSH}$ and cortisol. Neuro-imaging including multiplanar magnetic resonance imaging (MRI) for brain with and without contrast, computerized tomography (CT) for brain with and without contrast (bone window) and CT for paranasal sinuses and sella.

B) Surgical Procedures (Endoscopic Endonasal Trans-sphenoidal Approach):

- Endoscopic equipment: STORZ Xenon nova 300(20134020) with CONVMED3CCD Digital Camera and STORZ Xenon 300(20133120) with SCD Image 1hub22201020 Digital Camera. Rigid diagnostic endoscopes are used. There are three possible types which vary by length, diameter and direction of view.

- $0^{\circ}, 30^{\circ}, 45^{\circ}$ endoscopes length $18 \mathrm{~cm}$ and $4 \mathrm{~mm}$ diameter.

- $0^{\circ}$ and $30^{\circ}$ endoscopes, length $18 \mathrm{~cm}$ and $2.7 \mathrm{~mm}$ diameter.

- $0^{\circ}$ and $30^{\circ}$ endoscopes, length $30 \mathrm{~cm}$ and $4 \mathrm{~mm}$ diameter.

The endoscope was connected to a cable, which was connected to a light source, xenon cold light was preferred because it had spectral characteristics close to sunlight and its illumination was whiter than halogen light. The video camera and fiber optic light cable are connected to the video system and to the cold light source. The complete imaging system is positioned behind the patient's head on a mobile cart together with the monitor and video recorder.

After informed consent the patient put under general anesthesia with orotracheal intubation and given antibiotics, glucocorticoids, and antihistamines. We routinely use cefazolin (2 $\mathrm{g}$ intravenous), dexamethasone $(10 \mathrm{mg}$ intravenous $)$ and diphenhydramine (50 mg intravenous). Corticosteroids are not given to patients with Cushing's disease. Both a Foley catheter and arterial line are placed.

A cotton wools soaked with diluted adrenaline (1:100000) or with xylometazoline hydrochloride were positioned between the middle turbinate and the nasal septum to enlarge the space between them and obtain decongestion of the nasal mucosa, which had rich innervations and vascularization.

The patient was put in supine position with the head placed in rigid fixation, slightly extended and turned slightly to the right. To facilitate venous drainage, the head was elevated above the heart. Also, can be placed on a horseshoe. One advantage of avoiding rigid fixation is that the head could be moved during the case to improve exposure. In this case a skull clamp or headset should be used for navigation. The surgeons stand on either side of the patient during the majority of the procedure. Under endoscopic view, the inferior, middle, and superior turbinates are identified. The posterior medial aspect of the middle turbinate was removed by angled scissors, this was done in some cases and the head of the middle turbinate was delicately dislocated laterally to further widen the virtual space between the middle turbinate and the nasal septum and to create an adequate surgical pathway. After the middle and superior turbinates are retracted laterally, the sphenoid ostium is identified. The sphenoid ostium was enlarged and wide bilateral sphenoidotomies were performed, creating a large single cavity through which to work. The bone of the tuberculum sellae and the planum sphenoidale reaching the posterior ethmoid was removed laterally including the lateral tubercular strut to provide wide access to bilateral medial opticocarotid recesses.

The dura was incised in a midline position and in a linear or cruciate fashion. After the dura was opened, the pituitary gland can be mobilized laterally or inferiorly to increase exposure. Tumor resection and adhesions to the optic nerve, chiasma, and pituitary stalk were sharply dissected and extreme care was taken in separating the tumor from the hypothalamus. Exploration of the lateral sella with a blunt ring curette should be pursued gently to avoid injury to the cavernous sinus and adjacent cranial nerves. The superior intercavernous sinus was controlled either by electrocautery or by injection of hemostatic agents into the sinus.

Reconstruction of the skull base was performed using a fascia lata graft, followed by a vascularized nasoseptal flap, synthetic dural sealant and absorbable packing.

C) Post-operative management: All patients were admitted to neurosurgical intensive care unit (N.I.C.U) for at least the first day. Close clinical follow up (neurological, visual \& hormonal) to detect occurrence of other deficits. Nasal packs were removed on the second post-operative day and monitored for nasal or post nasal CSF drainage for at least several hours after 
removal of the packs. CT brain was done for cases with severe headache, sudden deterioration of vision or deterioration of the conscious level.

D) Follow up (clinically and radiologically) for six months: Scheduled clinical general and neurological examination and follow up of visual and hormonal disturbances. Post-operative magnetic resonance imaging (MRI) brain with contrast after 3 months.

\section{Ethical approval and written informed consent:}

An approval of the study was obtained from AlAzhar University Academic and Ethical Committee. Every patient signed an informed written consent for acceptance of the operation.

\section{Statistical analysis}

Data entry, processing and statistical analysis were carried out using MedCalc ver. 18.2.1 (MedCalc, Ostend, Belgium). Tests of significance (Mann-Whitney's and Chi square tests) were used. Data were presented and suitable analysis was done according to the type of data (parametric and non-parametric) obtained for each variable. P-values less than $0.05(5 \%)$ was considered to be statistically significant.

\section{RESULTS}

In the studied population, we found that, the mean age of all patients was $35.9 \pm 15$ years old and the mean disease duration was $3.9 \pm 1.3$ months. Regarding gender of the patients, the majority $(80 \%)$ of patients were females, while $20 \%$ were males.

Regarding baseline general neurological symptoms, $10 \%$ of patients had ANS deficit, cognitive dysfunction and DCL respectively.

Regarding visual affection symptoms, $80 \%$ of patients had diminution of vision and bitemporal hemianopia respectively.

Regarding ICT symptoms, $70 \%$ of patients had headache and vomiting, while $10 \%$ had seizures.

Regarding hypothalamic-pituitary symptoms, $20 \%$ of patients had obesity, $60 \%$ had fatigability, $30 \%$ had amenorrhea and $50 \%$ had sleep disturbances, while $10 \%$ had polyuria \& polydipsia.

Regarding baseline laboratory data, $10 \%$ of patients had high blood sugar, prolactin and GH respectively and $40 \%$ had low $\mathrm{T} 3$ and $\mathrm{T} 4$ while $30 \%$ had low cortisol levels.

Regarding baseline radiological data, the average tumor size was $4 \pm 1.09 \mathrm{~cm}^{3}$. Regarding shape of tumor, $50 \%$ had lobular shape and $50 \%$ had oval shape. Regarding tumor architecture, $60 \%$ were cystic and $40 \%$ were mixed.

Regarding extent of resection, $80 \%$ of patients had GTR, while $20 \%$ had STR (Table 1).

Table (1): Operative data (extent of resection) among 10 craniopharyngioma patients

\begin{tabular}{|l|c|c|}
\hline \multicolumn{2}{|l|}{ Variables } & \multicolumn{1}{|l|}{ Frequency (\%) } \\
\hline Extent of & GTR & $8(80 \%)$ \\
resection & STR & $2(20 \%)$ \\
\hline
\end{tabular}

GTR: Gross Total Resection. STR: Subtotal Resection.

Outcome data (post-operative outcomes): Regarding efficacy outcomes, $70 \%$ of patients had complete vision improvement, while $30 \%$ had partial improvement, achieving 70\% efficacy of resection operation (Table 2). Regarding safety outcomes, $10 \%$ had DCL and seizures, $50 \%$ had DI, while $30 \%$ had CSF rhinorrhea (Table 2, Fig. 1).

Table (2): Outcome data among 10 craniopharyngioma patients

\begin{tabular}{|c|c|c|}
\hline \multicolumn{2}{|l|}{ Variables } & $\begin{array}{c}\text { Frequency } \\
(\%)\end{array}$ \\
\hline $\begin{array}{l}\text { Favorable } \\
\text { outcomes } \\
\text { "Efficacy" }\end{array}$ & $\begin{array}{l}\text { Vision } \\
\text { improvement } \\
\text { Partial } \\
\text { improvement }\end{array}$ & $\begin{array}{l}7(70 \%) \\
3(30 \%)\end{array}$ \\
\hline $\begin{array}{l}\text { Un-favorable } \\
\text { outcomes } \\
\text { "Safety" }\end{array}$ & $\begin{array}{l}\text { DCL \& Seizures } \\
\text { DI } \\
\text { CSF Rhinorrhea }\end{array}$ & $\begin{array}{l}1(10 \%) \\
5(50 \%) \\
3(30 \%)\end{array}$ \\
\hline
\end{tabular}

DI: Diabetes Insipidus.

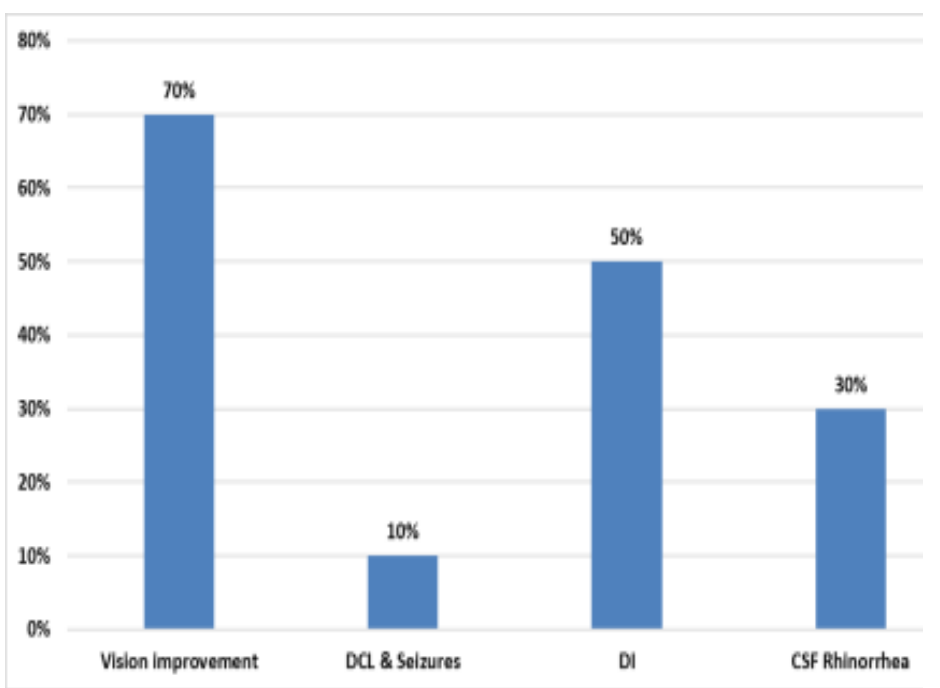

Figure (1): Outcome data among 10 craniopharyngioma patients.

Comparative studies: The 10 craniopharyngioma patients were classified according to efficacy outcome "complete visual improvement" into 2 independent groups:

- Complete visual improvement group (7 patients)

- Partial visual improvement group (3 patients)

Baseline clinical data: Comparative study between the 2 groups revealed; significant increase in diminution of vision in completely improved group compared to partially improved group with significant statistical difference $(p=0.021)$. Moreover, there was significant increase in sleep disturbances in partially improved group compared to completely improved group with significant statistical difference $(p=0.049)$ and there was non-significant difference as regards all the remaining clinical and neurological data $(\mathrm{p}>0.05)$ (Table 3). 
Table (3): Comparison between the 2 groups as regards baseline clinical and neurological data using MannWhitney's U and Chi square tests

\begin{tabular}{|c|c|c|c|c|}
\hline \multirow{2}{*}{\multicolumn{2}{|c|}{ Variable }} & $\begin{array}{c}\text { Completely } \\
\text { Improved (7) }\end{array}$ & \begin{tabular}{|c|} 
Partially \\
Improved (3) \\
\end{tabular} & \begin{tabular}{|c|} 
Mann-Whitney's U \\
test
\end{tabular} \\
\hline & & Median (IQR) & Median (IQR) & P value \\
\hline \multicolumn{2}{|l|}{ Age (years) } & $38(25.2-43.5)$ & $26(20.7-51.5)$ & $=0.8191$ \\
\hline \multicolumn{2}{|l|}{ Disease Duration (month) } & $4(3-5)$ & $4(2.5-4.7)$ & $=0.7268$ \\
\hline \multirow{2}{*}{\multicolumn{2}{|c|}{ Variable }} & \multirow{2}{*}{$\begin{array}{c}\text { Completely } \\
\text { improved } \\
\text { (7) }\end{array}$} & \multirow{2}{*}{$\begin{array}{l}\text { Partially } \\
\text { improved } \\
\text { (3) }\end{array}$} & Chi square test \\
\hline & & & & $P$ value \\
\hline Gender & $\begin{array}{l}\text { Female } \\
\text { Male }\end{array}$ & $\begin{array}{l}5(71.4 \%) \\
2(28.6 \%)\end{array}$ & $\begin{array}{c}3(100 \%) \\
0(0 \%)\end{array}$ & $=0.3261$ \\
\hline $\begin{array}{l}\text { ANS deficit } \\
\text { Cognitive dysfunction } \\
\text { DCL }\end{array}$ & $\begin{array}{l}+\mathrm{ve} \\
+\mathrm{ve} \\
+\mathrm{ve}\end{array}$ & $\begin{array}{l}0(0 \%) \\
0(0 \%) \\
0(0 \%)\end{array}$ & $\begin{array}{l}1(33.3 \%) \\
1(33.3 \%) \\
1(33.3 \%)\end{array}$ & $\begin{array}{l}=0.1266 \\
=0.1266 \\
=0.1266\end{array}$ \\
\hline $\begin{array}{l}\text { Diminution of vision } \\
\text { Bitemporal hemianopia }\end{array}$ & $\begin{array}{l}+\mathrm{ve} \\
+\mathrm{ve}\end{array}$ & $\begin{array}{l}7(100 \%) \\
6(85.7 \%)\end{array}$ & $\begin{array}{l}1(33.3 \%) \\
2(66.7 \%)\end{array}$ & $\begin{array}{l}=0.021 * \\
=0.5127\end{array}$ \\
\hline $\begin{array}{l}\text { Headache } \\
\text { Vomiting } \\
\text { Seizures }\end{array}$ & $\begin{array}{l}+ \text { +ve } \\
+\mathrm{ve} \\
+\mathrm{ve}\end{array}$ & $\begin{array}{c}5(71.4 \%) \\
5(71.4 \%) \\
0(0 \%)\end{array}$ & $\begin{array}{l}2(66.7 \%) \\
2(66.7 \%) \\
1(33.3 \%)\end{array}$ & $\begin{array}{l}=0.8864 \\
=0.8864 \\
=0.1266\end{array}$ \\
\hline $\begin{array}{l}\text { Obesity } \\
\text { Fatigability } \\
\text { Amenorrhea } \\
\text { Sleep disturbances } \\
\text { Polyuria \& polydipsia }\end{array}$ & $\begin{array}{l}\text { +ve } \\
+\mathrm{ve} \\
+\mathrm{ve} \\
+\mathrm{ve} \\
+\mathrm{ve}\end{array}$ & $\begin{array}{c}2(28.6 \%) \\
3(42.9 \%) \\
1(14.3 \%) \\
2(28.6 \%) \\
0(0 \%) \\
\end{array}$ & $\begin{array}{c}0(0 \%) \\
3(100 \%) \\
2(66.7 \%) \\
3(100 \%) \\
1(33.3 \%) \\
\end{array}$ & $\begin{array}{l}=0.3261 \\
=0.1088 \\
=0.1161 \\
=0.049 * \\
=0.1266\end{array}$ \\
\hline
\end{tabular}

IQR: inter-quartile range. $*$ Percentage of Column Total.

- Baseline laboratory data: Comparative study between the 2 groups revealed non-significant difference as regards all baseline laboratory data $(\mathrm{p}>0.05)$.

- Baseline radiological data: Comparative study between the 2 groups revealed non-significant difference as regards all baseline radiological data $(\mathrm{p}>0.05)$.

- Operative data (extent of resection): Comparative study between the 2 groups revealed non-significant difference as regards extent of resection ( $\mathrm{p}>0.05)$.

- GTR achieved $71.4 \%$ success rate of completely improved patients, while STR achieved only $28.6 \%$ success rate of completely improved patients (Table 4).

Table (4): Comparison between the 2 groups as regards extent of resection using Chi square test

\begin{tabular}{|l|c|c|c|c|}
\hline \multicolumn{2}{|c|}{ Variable } & $\begin{array}{c}\text { Complete } \\
\text { improvement } \\
\text { (7) }\end{array}$ & $\begin{array}{c}\text { Partial } \\
\text { improvement } \\
(\mathbf{3})\end{array}$ & Chi square test \\
\cline { 3 - 5 } Extent of resection & GTR & $\mathbf{5 ( 7 1 . 4 \% )}$ & $3(100 \%)$ & P value \\
\hline * Percentage of Column Total. & STR & $\mathbf{2 ( 2 8 . 6 \% )}$ & $0(0 \%)$ & $=0.326$ \\
\hline
\end{tabular}

Outcome data (post-operative complications): Comparative study between the 2 groups revealed non-significant difference as regards all post-operative complications ( $p>0.05$ ) (Table 5).

Table (5): Comparison between the 2 groups as regards post-operative complications using Chi square test

\begin{tabular}{|c|c|c|c|c|}
\hline \multicolumn{2}{|l|}{ Variable } & $\begin{array}{c}\begin{array}{c}\text { Complete } \\
\text { improvement } \\
(7)\end{array} \\
0\left(0^{\circ}()\right)\end{array}$ & $\begin{array}{c}\text { Partial } \\
\text { improvement } \\
\text { (3) }\end{array}$ & $\begin{array}{c}\text { Chi square test } \\
\text { P value } \\
\end{array}$ \\
\hline $\begin{array}{l}\text { Complications } \\
\text { outcomes } \\
\text { "Safety" }\end{array}$ & $\begin{array}{l}\text { DCL \& Seizures } \\
\text { DI } \\
\text { CSF Rhinorrhea }\end{array}$ & $\begin{array}{c}0(0 \%) \\
4(57.1 \%) \\
2(28.6 \%)\end{array}$ & $\begin{array}{l}1(33.3 \%) \\
1(33.3 \%) \\
1(33.3 \%)\end{array}$ & $\begin{array}{l}=0.126 \\
=0.512 \\
=0.886\end{array}$ \\
\hline
\end{tabular}




\section{CASE SAMPLES}

Case 1: 39 years old female patient complaining of diminution of vision for 6 months. By examination, visual acuity of the right eye was $6 / 60$ and the left eye was $6 / 18$. Hormonal profile was normal. MRI brain with contrast was done revealing sellar \& suprasellar mass mixed in consistency. Gross total resection was achieved. Patient had transient postoperative DI, which was completely resolved on follow up and the visual disturbance improved postoperatively (Fig. 2a, 2b).
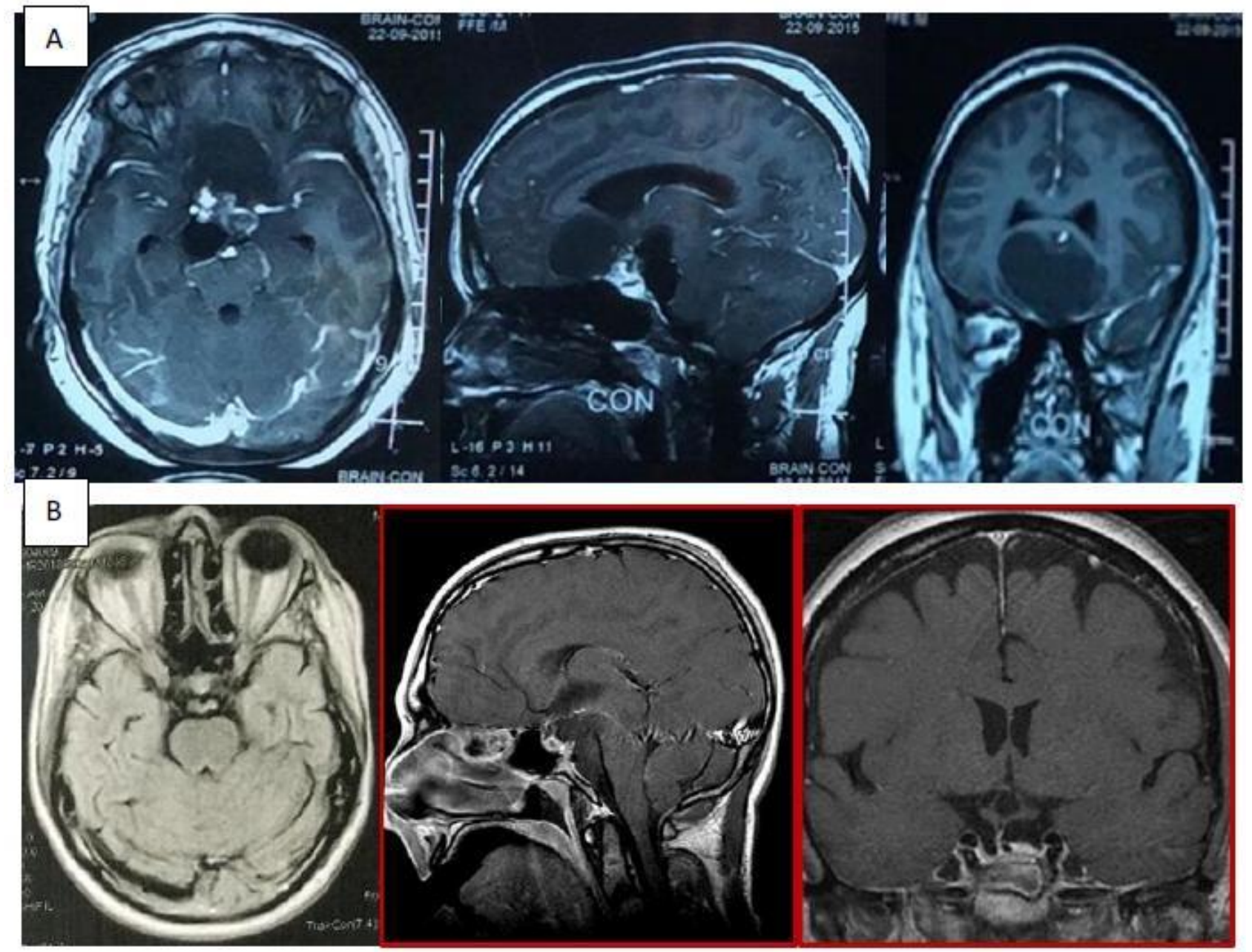

Figure (2): (A) Preoperative Axial, Sagittal and coronal contrast-enhanced T1-weighted MR images of a case of craniopharyngioma with postfixed chiasma. (B) Postoperative Axial, Sagittal and coronal T1- weighted MR images of a case of craniopharyngioma with postfixed chiasma.

\section{DISCUSSION}

Craniopharyngiomas are considered very difficult lesions to treat because of an extremely variable growth pattern. Controversies still exist concerning surgical management. In recent years, different surgical centers throughout the world, already confident with the endoscopic endonasal management of pituitary tumors. They began to perform "pure" endoscopic endonasal procedures intended for removal of craniopharyngiomas.

Our study included 10 patients whose ages ranged from 19 to 60 years (mean age 39.5 years), which is consistent with other big series as Park $\boldsymbol{e t}$ al. (6) study which included 111 adult patients (95.6\%) with a mean age of 43.8 years (range 14-74 years) and 5 children (4.4\%) with a mean age of 15.6 year (range
14-17) and Cavallo et al. ${ }^{(7)}$ study, which included $83(81.6 \%)$ adult patients with a mean age of 50.36 years (range 18-83 years) and 20 children (19.4\%) with a mean age of 10.1 years. This was attributed to the fact that it was our initial experience with this technique.

The chief complaint in our study was visual disturbance in 8 cases $(80 \%)$, endocrinopathy in 4 cases $(40 \%)$, and headache in 7 cases $(70 \%)$. This is compatible with Park et al. ${ }^{(\boldsymbol{6})}$ results where vision loss was the most common presenting symptom (83\%) followed by headache (48\%) and endocrinopathy (33\%), while Cavallo et al. ${ }^{(7)}$ found that visual disturbances were present in $76.7 \%$ of patients followed by endocrinopathy in $56.6 \%$ of adult patients 
and hypothalamic symptoms in $24.3 \%$ of adult patients.

Our patients underwent a detailed neuroophthalmological examination before and after surgery. Of the 8 patients with preoperative visual deficits, $70 \%$ had complete resolution of their visual defect and $30 \%$ had improvement with partial resolution, achieving $70 \%$ efficacy of resection operation. The 10 craniopharyngioma patients were classified according to efficacy outcome "complete visual improvement", into 2 independent groups: Complete visual improvement group (7 patients) and partial visual improvement group (3 patients). Comparative study between the 2 groups revealed significant increase in diminution of vision in completely improved group; compared to partially improved group; with significant statistical difference $(\mathrm{p}=0.021)$. These findings are consistent with those of Park et al. ${ }^{(6)}$ where of 89 patients with preoperative visual deficits, $76 \%$ experienced improvement and $49 \%$ experienced normalization of visual deficits postoperatively. Overall, a sparse $7.3 \%$ experienced visual deterioration postoperatively. Also, Cavallo et al. ${ }^{(7)}$ found that of 103 patients, improvement of the visual deficit occurred in $74.7 \%$, normalization of the deficiency was achieved in $5.1 \%$, while $17.7 \%$ remained unchanged and $2.5 \%$ had worsening of preoperative visual deficit. The similarity of the results between different series shows the effectiveness of Endoscopic Endonasal Approach in chiasmal decompression.

In terms of endocrinopathy, panhypopituitarism and DI are particularly common following the resection of Craniopharyngiomas. However, in our study, none of the patients experienced postoperative panhypopituitarism, 4 of the patients had preoperative panhypopituitarism (40\%), which improved postoperatively. 5 patients developed postoperative DI, 4 of them had it totally resolved, while only 1 patient (20\%) suffered from permanent DI. Comparative study between the 2 groups which were classified according to efficacy outcome revealed nonsignificant difference as regards all post-operative complications $(\mathrm{p}>0.05)$. Our results are relatively similar to those of Gardner et al. ${ }^{(8)}$ where only 2 patients developed new-onset panhypopituitarism following surgery (18\%). Only 1 (8\%) of 12 patients who underwent long-term follow-up suffered permanent DI. Four others developed temporary DI in the postoperative period, which showed resolution during the last follow-up without further treatment. Our results disagree with Park $\boldsymbol{e t}$ al. ${ }^{\left({ }^{(6)}\right.}$ study as none of the 29 patients with preoperative panhypopituitarism experienced endocrine function recovery. Moreover, of the 36 patients who had normal anterior pituitary function preoperatively, 5 (14\%) developed partial hypopituitarism and 16 (44\%) developed panhypopituitarism. Among the 98 patients without preoperative DI, 73 (74\%) had no or transient DI and $25(25.5 \%)$ developed permanent DI postoperatively. Additionally, the results of Cavallo et al. ${ }^{(7)}$ and his colleagues showed that in $43.8 \%$ of cases that presented with normal anterior pituitary function, there was deterioration and among cases with preoperative panhypopituitarism, only $8 \%$ improved. Also, preoperative DI remained unchanged in $100 \%$ of patients and the new onset of DI was $48.1 \%$. The statistical difference between our study and number of other studies might be due to our small sample size and the low incidence of preoperative panhypopituitarism. However, the incidence of postoperative diabetes insipidus was almost the same and showed to be higher in patients with lesions involving the pituitary stalk (trans-infundibular type 2 lesions) according to Kassam et al. ${ }^{(9)}$ classification for craniopharyngioma.

We achieved gross total resection (GTR) in 8 patients $(80 \%)$ and subtotal resection (STR) in 2 patients (20\%). GTR achieved (71.4\%) success rate of completely improved patients, while STR achieved only (28.6\%) success rate of completely improved patients. The extent of total resection was acceptable when compared to other series in literature such as that of Cavallo et al. ${ }^{(7)}$ where a higher GTR rate was achieved in supra-diaphragmatic retro-chiasmatic lesions (80\%) and pre-chiasmatic lesions group (72.4\%) in comparison with the pre \& retrochiasmatic lesions (39.1\%). Moreover, safe and radical resection of supradiaphragmatic lesions depends heavily on the relation of the tumor to the infundibulum, a fact emphasized by Gardner et al. ${ }^{(8)}$ study. Preservation of endocrine function while achieving respectable extent of resection can be achieved in types I (preinfundibular) and III (retroinfundibular) tumor where the stalk can be separated and potentially preserved, while preservation of function must be weighed against the recurrence risk in type II (transinfundibular) tumors.

In terms of the extent of resection, we found a significant statistical difference when our results were compared to a transcranial approach study on 20 patients by Sun $\boldsymbol{e t}$ al. ${ }^{(\mathbf{1 0})}$ where GTR was achieved in 18 patients (90\%) and only 2 patients $(10 \%)$ had STR. Yet, no significant statistical relation was found between GTR via transcranial approach and better postoperative endocrinological outcome.

On the contrary, incidence of new endocrinopathy in the transcranial literature have ranged from $24 \%$ to $66 \%$ for panhypopituitarysm and $43 \%$ to $79 \%$ for DI, while in endonasal series it is $18 \%$ to $67 \%$ for panhypopituitarism and $8 \%$ to $48 \%$ for permanent DI. The improved visualization of the infundibulum, pituitary stalk and superior hypophyseal branches may explain these differences (11). 
In our series, the characteristics of the lesions revealed that tumor consistency was mixed (solidcystic) in $40 \%$ (4 patients), cystic in $60 \%$ (6 patients). Calcifications of variable degree were found in $100 \%$ (10 patients) of cases. However, we didn't find any significant statistical correlation between tumor consistency and extent of resection. Even though in some studies as Park et al. ${ }^{\left({ }^{(6)}\right.}$ or Cavallo et al. ${ }^{(7)}$ the extent of resection was slightly higher in purely cystic lesions than in mixed lesions.

The most common surgical complication in our series was cerebrospinal fluid (CSF) leakage in 3 patients $(30 \%)$. The most common medical complication showed to be diabetes insipidus in 5 patients (50\%), disturbed conscious level (DCL) and seizures in 1 patient $(10 \%)$. Our results are closely compatible with Yadav et al. ${ }^{(12)}$ as postoperative CSF leakage was the most common complication encountered. All patients with CSF leakage underwent a primary endoscopic repair (in the same operation). In our trials, none of the patients had a preoperative lumbar drain as elected by our surgeons.

Finally, regarding efficacy outcomes, $70 \%$ of patients had complete vision improvement, while $30 \%$ had partial improvement, achieving $70 \%$ efficacy of resection operation. Regarding safety outcomes, $10 \%$ had DCL and seizures, 50\% had DI, while 30\% had CSF rhinorrhea. GTR achieved $71.4 \%$ success rate of completely improved patients, while STR achieved only $28.6 \%$ success rate of completely improved patients.

\section{CONCLUSION}

Endoscopic Endonasal Approach (EEA) is an effective surgical treatment for removal of craniopharyngiomas in terms of surgical outcome and tumor control. Along with technological progress and increasing surgical experience, the endoscopic endonasal approach has emerged as a valid surgical technique to manage properly selected craniopharyngiomas. It provides an adequate route to the infra- and supradiaphragmatic midline craniopharyngiomas and also giving the opportunity to manage lesions extending into the third ventricle. The extent of resection, along with the choice of surgical approach, has a significant effect on the ophthalmological and endocrinological outcome after craniopharyngioma resection.

This small case series appears to support the use of endoscopic endonasl approach to provide a high rate of endocrine function preservation and visual recovery, while achieving respectable extent of resections. Other series in the literature demonstrate reasonable resection rates with favorable ophthalmological and endocrinological outcome. However, expansion of the series, both in terms of number of patients and period of follow up is critical for accurate evaluation of the endoscopic endonasal approach.

\section{Conflict of interest}

The authors declared that there was no conflict of interest.

\section{REFERENCES}

1. Shibata T, Tanikawa M, Sakata T et al. (2018): Urgent Optic Nerve Decompression via an Endoscopic Endonasal Transsphenoidal Approach for Craniopharyngioma in a 12-Month-Old Infant: A Case Report. Pediatr Neurosurg., 53: 182-187.

2. Ozgural O, Kahilogullari G, Dogan I et al. (2018): Single-Center Surgical Experience of the Treatment of Craniopharyngiomas with Emphasis on the Operative Approach: Endoscopic Endonasal and Open Microscopic Transcranial Approaches. Journal of Craniofacial Surgery, 29 (6): 572-78.

3. O'steen L, Indelicato J (2018): Advances in the management of craniopharyngioma. F1000 Research, Pp: 7. https://f1000research.com/articles/7-1632

4. Graffeo S, Perry A, Link J et al. (2018): Pediatric Craniopharyngiomas: A Primer for the Skull Base Surgeon. J Neurol Surg B Skull Base, 79 (1): 65-80.

5. Younus I, Forbes A, Ordóñez-Rubiano G et al. (2018): Radiation therapy rather than prior surgery reduces extent of resection during endonasal endoscopic reoperation for craniopharyngioma. Acta neurochirurgica, 60 (7): 1425-1431.

6. Park HR, Kshettry VR, Farrell CJ et al. (2017): Clinical Outcome after Extended Endoscopic Endonasal Resection of Craniopharyngiomas: Two-Institution Experience. World Neurosurg [Internet]. Elsevier Inc., 103: 465-74.

7. Cavallo LM, Frank G, Abianca PC et al. (2014): The endoscopic endonasal approach for the management of craniopharyngiomas: a series of 103 patients. J Neurosurg., 121: 100-13.

8. Gardner PA, Kassam AB, Snyderman CH et al. (2008): Outcomes following endoscopic, expanded endonasal resection of suprasellar craniopharyngiomas: a case series. Journal of Neurosurgery, 109(1): 6-16.

9. Kassam AB, Gardner PA, Snyderman CH et al. (2008): Invasive M. Expanded endonasal approach, a fully endoscopic transnasal approach for the resection of midline suprasellar. craniopharyngiomas: a new classification based on the infundibulum. J Neurosurg., 108: 715-28.

10. Sun F, Sun X, Du X et al. (2017): Factors related to endocrine changes and hormone substitution treatment during pre-and post-operation stages in craniopharyngioma. Oncol Lett., 13 (1): 250-2.

11. Sua C, Devaney KO, Genden EM et al. (2011): Craniopharyngioma: A pathologic, clinical, and surgical review. Head Neck, 34 (7): 1036-44.

12. Yadav YR, Nishtha Y, Vijay $P$ et al. (2015): Endoscopic endonasal trans-sphenoid management of craniopharyngiomas.Asian J Neurosurg., 10 (1): 10-16. 